\title{
Hypoxia in atherosclerosis and inflammation
}

Citation for published version (APA):

Marsch, E., Sluimer, J. C., \& Daemen, M. J. A. P. (2013). Hypoxia in atherosclerosis and inflammation. Current Opinion in Lipidology, 24(5), 393-400. https://doi.org/10.1097/MOL.0b013e32836484a4

Document status and date:

Published: 01/10/2013

DOI:

10.1097/MOL.0b013e32836484a4

Document Version:

Publisher's PDF, also known as Version of record

Document license:

Taverne

Please check the document version of this publication:

- A submitted manuscript is the version of the article upon submission and before peer-review. There can be important differences between the submitted version and the official published version of record.

People interested in the research are advised to contact the author for the final version of the publication, or visit the DOI to the publisher's website.

- The final author version and the galley proof are versions of the publication after peer review.

- The final published version features the final layout of the paper including the volume, issue and page numbers.

Link to publication

\footnotetext{
General rights rights.

- You may freely distribute the URL identifying the publication in the public portal. please follow below link for the End User Agreement:

www.umlib.nl/taverne-license

Take down policy

If you believe that this document breaches copyright please contact us at:

repository@maastrichtuniversity.nl

providing details and we will investigate your claim.
}

Copyright and moral rights for the publications made accessible in the public portal are retained by the authors and/or other copyright owners and it is a condition of accessing publications that users recognise and abide by the legal requirements associated with these

- Users may download and print one copy of any publication from the public portal for the purpose of private study or research.

- You may not further distribute the material or use it for any profit-making activity or commercial gain

If the publication is distributed under the terms of Article $25 \mathrm{fa}$ of the Dutch Copyright Act, indicated by the "Taverne" license above, 


\title{
Hypoxia in atherosclerosis and inflammation
}

\author{
Elke Marsch $^{\mathrm{a}}$, Judith C. Sluimer ${ }^{\mathrm{a}}$, and Mat J.A.P. Daemen ${ }^{\mathrm{b}}$
}

\begin{abstract}
Purpose of review
Hypoxia triggers various cellular processes, both in physiological and pathological conditions, and has recently also been implicated in atherosclerosis. This review summarizes the recent evidence for the presence and the role of hypoxia in atherosclerosis. Additionally, it will elucidate on hypoxic signaling, which is interlinked with inflammatory signaling, and discuss recent advances in imaging of hypoxia in atherosclerosis.
\end{abstract}

\begin{abstract}
Recent findings
Hypoxia is present in atherosclerotic plaques in humans and animal models, and systemic hypoxia promotes atherosclerosis. Hypoxia stimulates proatherosclerotic processes, like deficient lipid efflux, inflammation, interference with macrophage polarization and glucose metabolism. However, the molecular mechanism of hypoxia-mediated atherogenesis remains unclear.

Noninvasive imaging directly targeting plaque hypoxia has been applied in animal models of atherosclerosis, but remains to be validated in humans. Meanwhile, the metabolic marker

${ }^{18}$ F-fluorodeoxyglucose, used to detect human atherosclerosis in vivo, may serve as an indirect marker of plaque hypoxia due to enhanced glucose uptake in anaerobic metabolism.
\end{abstract}

\section{Summary}

Recent studies underscore the proatherogenic role of hypoxia in macrophage lipid and glucose metabolism, inflammation and polarization. These studies provide new insights into the pathogenesis of atherosclerosis and unravel novel therapeutic targets and new options for noninvasive imaging of human atherosclerotic plaques.

\section{Keywords}

atherosclerosis, hypoxia, imaging, macrophages, metabolism

\section{INTRODUCTION: EVIDENCE OF HYPOXIA IN ATHEROSCLEROSIS - A HISTORICAL VIEW}

Low oxygen tension, hypoxia, is an important stimulus of both pathological and physiological processes including angiogenesis, inflammation, metabolism and apoptosis. All of these processes are implicated in atherogenesis. Arterial wall hypoxia has been extensively studied using microelectrodes in vitro and in vivo in healthy arteries and atherosclerosis injury models in rabbits [1-5]. More recently, Björnheden et al. [6,7] showed zones of hypoxia in rabbit atherosclerotic plaques, using the imidazole derivate 7-[4'-(2-nitroimidazol-1-yl)butyl)-theophylline (NITP)], and suggested a co-localization of hypoxia with foam cells (macrophages). NITP undergoes intracellular nitroreduction (mainly by cytochrome p450) [8], resulting in reactive intermediates. In cells with a partial oxygen pressure below $10 \mathrm{mmHg}$, these intermediates form stable adducts with cellular thiol groups in proteins, peptides and amino acids [9].
Using the imidazole derivate pimonidazole, we recently conclusively demonstrated the presence of hypoxia in human atherosclerotic plaques in vivo. As for rabbit atherosclerosis, macrophages are the major cell types in human plaques that display signs of hypoxia, with co-existent expression of hypoxiainducible factor $1 \alpha$ (Hif- $1 \alpha$ ) and vascular endothelial growth factor (VEGF). Furthermore, hypoxia correlated with intra-plaque angiogenesis [10]. Autoradiography of the imidazole marker $\left[{ }^{18} \mathrm{~F}\right]$-EF5

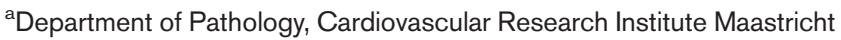
(CARIM), Maastricht University Medical Center, Maastricht and ${ }^{b}$ Department of Pathology, Amsterdam Medical Centre, Amsterdam, the Netherlands

Correspondence to Mat J.A.P. Daemen, MD, PhD, Academic Medical Centre, Department of Pathology, Meibergdreef 9, 1105 AZ Amsterdam, The Netherlands. Tel: +31 20566 7519; fax: +31 20566 9523; e-mail: m.j.daemen@amc.uva.nl
}

Curr Opin Lipidol 2013, 24:393-400

DOI:10.1097/MOL.0b013e32836484a4 


\section{KEY POINTS}

- Atherosclerotic plaque hypoxia is present across species.

- Hypoxia stimulates atherosclerosis.

- Hypoxia and inflammation share similar pathways, including NF- $\mathrm{kB}$ activation.

- Hypoxia alters macrophage lipid and glucose metabolism, inflammation and polarization and vice versa.

- Noninvasive plaque imaging may target hypoxia directly using imidazole analogues or indirectly using 18F-FDG PET.

[2-(2-nitro-1H-imidazol-1-yl)-N-(2,2,3,3,3-pentafluo ropropyl)] was also able to detect hypoxia in atherosclerotic plaques in $\mathrm{LDLR}^{-/-} \mathrm{ApoB}^{100 / 100}$ and IGF-II/ $\mathrm{LDLR}^{-/-} \mathrm{ApoB}^{100 / 100}$ mice [11]. Murine plaque hypoxia was also confirmed in $\mathrm{LDLR}^{-/-}$mice in vivo using pimonidazole and pimonidazole positivity again co-localized with macrophages [12"]. On the basis of these studies, the presence of hypoxia in human and murine atherosclerotic plaques is nowadays widely accepted; however, the functional involvement of hypoxia in atherogenesis remains unclear.

Cells respond to hypoxic conditions by adjusting metabolism, angiogenesis, inflammation, migration, endothelial dysfunction and cell survival signaling $\left[13,14^{\prime \prime}, 15\right]$. These processes mainly involve the transcription factor Hif-1 [16]. Hif-1 is composed of a $\alpha$ and $\beta$ subunit, with Hif- $1 \alpha$ being continuously degraded under normoxic conditions, whereas hypoxia increases its stability and transcriptional activity [17]. In human atherosclerotic plaques, we showed co-expression of the hypoxic marker pimonidazole and Hif- $1 \alpha$, suggesting a role of Hif- $1 \alpha$ in atherosclerosis [10]. However, it should be noted that Hif- $1 \alpha$ can also be stabilized under normoxic conditions and therefore does not exclusively represent hypoxia. Atherosclerotic factors including reactive oxygen species (ROS) [18], thrombin [19], lipopolysaccharide [20], oxidized LDL (oxLDL) [21], protein kinase $\mathrm{C}$ and phosphatidylinositide 3-kinase pathways [22] have also been shown to promote Hif- $1 \alpha$ stabilization in normoxia.

In this review, we will summarize the recent findings on a causal role for hypoxia-driven signaling in atherogenesis. As macrophages present the main hypoxic component of atherosclerotic plaques, we will focus on oxygen deprivation-mediated disturbances in macrophage functions, such as lipid and glucose metabolism, polarization and inflammatory signaling.

\section{ATHEROGENESIS: HYPOXIA-DRIVEN?}

Atherosclerotic vascular disease is the leading cause of morbidity and mortality in the industrialized world [23]. Evidence for a clinically relevant and progressive role of hypoxia in atherosclerosis is provided by obstructive sleep apnea (OSA) patients. OSA patients suffer from chronic intermittent cycles of hypoxia and reoxygenation [chronic intermittent hypoxia (CIH)] [24] and present with an increased risk for atherosclerosis and subsequent cardiovascular disease [25-30].

$\mathrm{CIH}$ is believed to be the major cause of OSAassociated atherosclerotic cardiac events (reviewed in [31]), in parts, by CIH-induced oxidative stress, which is elevated in OSA patients [32]. Even though local plaque hypoxia has not been shown in OSA patients so far, CIH models suggest a proatherogenic role of systemic hypoxia in atherosclerosis. Also, $\mathrm{CIH}$ induced atherosclerosis in C57Bl6 mice fed a high-cholesterol diet, whereas C57Bl6 mice subjected to high-cholesterol diet alone did not show lesion development. Exposure of $\mathrm{ApoE}^{-1-}$ mice to $\mathrm{CIH}$ accelerated atherosclerosis progression on high-cholesterol diet but also on normal chow [33-36]. Conversely, early signs of atherosclerosis, including arterial wall thickening and stiffness in OSA patients, can be reversed by continuous positive airway pressure therapy (CPAP) $[37,38]$. $\mathrm{CPAP}$ reverses upper airway narrowing by delivering compressed air, making unobstructed breathing possible and restoring hypopneas and apneas.

Additionally, hyperbaric oxygen treatment (HBOT, 2.4-2.5 atm, 100\% $\mathrm{O}_{2}$ ) reduced atherosclerosis in both rabbit and mouse models. It increased antioxidant enzymes and attenuated both lipid oxidation and the proinflammatory immune response [39-41]. In humans, HBOT improved atherosclerosis in patients with diabetic feet and in a patient with atherosclerotic cerebral infarction [42,43]. Unfirer et al. [44] proposed that the advantageous effect of HBOT on regression of atherosclerosis and diabetes mellitus might be due to a reoxygenation-mediated restoration of endothelial function. However, the mechanism underlying the beneficial effect of systemic reoxygenation on atherosclerosis and the effect on plaque hypoxia remains unclear. Moreover, the direct link between HBOT and atherosclerosis regression, as shown in animal models and case reports, remains to be confirmed in large-scale human atherosclerosis studies.

In conclusion, hypoxia is present in atherosclerotic plaques and systemic oxygen alterations in $\mathrm{CIH}$ and HBOT suggest a proatherosclerotic effector role of systemic hypoxia. However, whether this effect is mediated by local changes in plaque hypoxia is 
unclear and the underlying molecular mechanism remains obscure.

\section{HYPOXIA AND INFLAMMATION SHARE SIMILAR PATHWAYS: IS NF=KB THE KEY?}

Oxygen demand, and thus hypoxia, is particularly elevated at sites of inflammation, for example, wounds or atherosclerotic lesions [45"]. In this respect, it is not surprising that hypoxia and inflammatory responses share similar intracellular pathways, including metabolic alterations, macrophage phenotype switching and oxidative stress signaling. In this review, we will discuss the recent advances in hypoxia and inflammation signaling in atherosclerosis.

Hypoxia has mainly been studied with respect to lipid metabolism, as LDL modification and accumulation in the vessel wall and foam cell formation present critical steps in atherogenesis. Hypoxia enhances LDL oxidation, promotes triglyceride synthesis and loading of foam cells $\left[46^{*}, 47\right]$, inhibits cholesterol influx and enhances LDL affinity of macrophages [48] (extensively reviewed in [49"]). Along this line, foam cell formation could be inhibited in vitro by Hif- $1 \alpha$ RNA interference [50]. Mechanistically, the dyslipidemic effect of hypoxia has been linked with LXR expression and downregulation of cholesterol efflux receptors, such as ATP-binding cassette transporter (ABCA-1) [49",51]. In fact, Hif- $1 \alpha$ overexpression reduced cholesterol efflux from macrophages, which was even further decreased upon hypoxia [51]. A recent study now showed that another inflammatory transcription factor, nuclear factor kappa-light-chain-enhancer of activated B cells (NF-кB), was required for cholesterol efflux/uptake receptors ABCA-1 and SR-B1 protein expression in $\mathrm{CIH}$-induced atherosclerosis. Additionally, NF- $\mathrm{kB}$ subunit $\mathrm{p} 50^{-/-}$mice presented with reduced hyperlipidemia and foam cell formation in CIH-induced atherosclerosis [52"]. This confirms earlier findings, where ${\mathrm{p} 50^{-1-}}^{-}$attenuated atherosclerosis development in mice and reduced oxLDL uptake by $\mathrm{p} 50^{-/-}$macrophages, also in the absence of systemic hypoxia [53]. Another study showed that the hypoxic effect on lipid clearance was mediated by inhibition of lipoprotein lipase (LpL) and that this effect was independent of NF$\kappa \mathrm{B}\left[54^{\prime \prime}\right]$. In addition to the NF-кB-mediated dyslipidemic effects, NF- $\mathrm{B}$ contributed to macrophage differentiation, recruitment and foam cell formation [55], as well as endothelial dysfunction in chronic intermittent hypoxia models [56"].

In conclusion, hypoxia and inflammation share common signaling pathways, amongst others NF-кB activation. In concert, hypoxia and inflammation affect multiple processes, like lipid metabolism and cholesterol efflux, endothelial dysfunction and inflammation.

\section{HYPOXIA ALTERS GLUCOSE METABOLISM AND OXIDATIVE STRESS SIGNALING AND VICE VERSA}

Chronic inflammation is a feature of atherosclerosis and mounting an inflammatory response is an energy-intensive process. At sites of inflammation, macrophages rapidly switch from a resting to an activated state, resulting in increased cytokine production, enhanced phagocytosis and antigen presentation, all resulting in excessive ATP con-

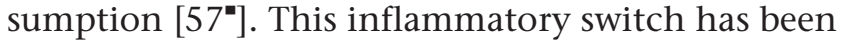
shown to be at least partially mediated by Hif- $1 \alpha$ in both normoxic and hypoxic conditions $[58,59]$ and is accompanied by a metabolic shift towards glycolysis, a phenomenon known as the Warburg effect. The Warburg effect describes the switch from oxygen-dependent mitochondria-mediated oxidative phosphorylation (OXPHOS) to glycolysis in tumor cells and highly proliferative cells. This switch can occur both in normoxic and hypoxic conditions and thus involves both aerobic and anaerobic glycolysis [60,61]. It is well established that aerobic metabolism via OXPHOS produces more ATP per glucose molecule (in fact 36 ATP) than glycolysis. Yet, cancer and inflammatory cells decide for a seemingly less efficient metabolism via glycolysis, with only two ATP being produced per glucose molecule. This discrepancy can be explained by looking at metabolism as an interlinked network, rather than pathways. During glycolysis, precursors of amino acid synthesis and nucleotide anabolism are generated, which are crucial for biomass accumulation and proliferation [61]. If nutrients are abundant, cells are hence easily capable of maintaining homeostasis by relying purely on glycolysis, both in inflammation and hypoxia.

Upon inflammation and hypoxia, $\mathrm{T}$ cells and macrophages switch their metabolism towards glycolysis, with macrophages presenting with a more proinflammatory M1-like phenotype [62-64]. In fact, Folco et al. [65] recently demonstrated that hypoxia rather than inflammation promotes glucose uptake by macrophages in vitro. M2 macrophages were shown to maintain oxidative phosphorylation for ATP production (reviewed in [66"]). Also in rabbit atherosclerotic lesions, hypoxic macrophages showed increased glucose consumption and ATP depletion, suggesting the Warburg effect in atherosclerosis. In vitro, hyperoxic reoxygenation of rabbit plaques could reverse ATP depletion, whereas normoxic conditions could 
not, suggesting that oxygen availability rather than glucose concentration is the limiting factor in ATP production within the plaques [67]. In turn, increased glycolysis promotes lactate production and acidification of the plaque environment. In fact, elevated blood lactate has recently been associated with increased carotid atherosclerotic wall thickness in humans, although this was partially related to insulin resistance [68]. As plaque and systemic acidification are proatherogenic $[69,70]$, enhanced lactate due to increased glycolysis may contribute to atherogenesis.

Apart from enhanced lactate production, hypoxia results in increased ROS production by a dysregulated mitochondrial respiratory chain (reviewed in [71]). ROS are implicated in oxLDL formation, endothelial activation, monocytederived macrophage recruitment, activation and death, vascular smooth muscle cell proliferation and death, and matrix remodeling $[72,73]$. Mitochondria, which are majorly dependent on oxygen during respiration, sense oxygen depletion and subsequently release ROS into the cytosol. ROS in turn stabilizes Hif- $1 \alpha$ via various pathways, including inhibition of prolyl hydroxylase-mediated Hif hydroxylation (reviewed in [74]). Macrophages, representing the largest hypoxic fraction in atherosclerosis [10], are also the main source of ROS and oxidative stress in the plaque [75"'], suggesting a link between hypoxia and ROS in plaque progression. In accordance, ROS inhibition by statins has been shown to improve hypoxia-induced endothelial dysfunction [76]. Also, OSA patients present with elevated oxidative stress levels and ROS-mediated endothelial dysfunction $\left[37,77,78^{*}\right.$, 79,80"]. These data confirm a metabolic switch towards glycolysis in atherosclerotic macrophages, with subsequent lactate and ROS production contributing to endothelial dysfunction and plaque advancement. However, whether hypoxia promotes this glycolytic shift, or whether hypoxia is secondary to enhanced glycolysis and inflammation in vivo, remains to be elucidated. On the basis of the fact that even small mouse lesions present hypoxic areas, we postulated that macrophage oxygen demand rather than impaired oxygen diffusion promotes hypoxia in macrophages in atherosclerotic plaques [10]. This would suggest that plaque hypoxia is secondary to a metabolic switch towards glycolysis during atherosclerosis (see Fig. 1).

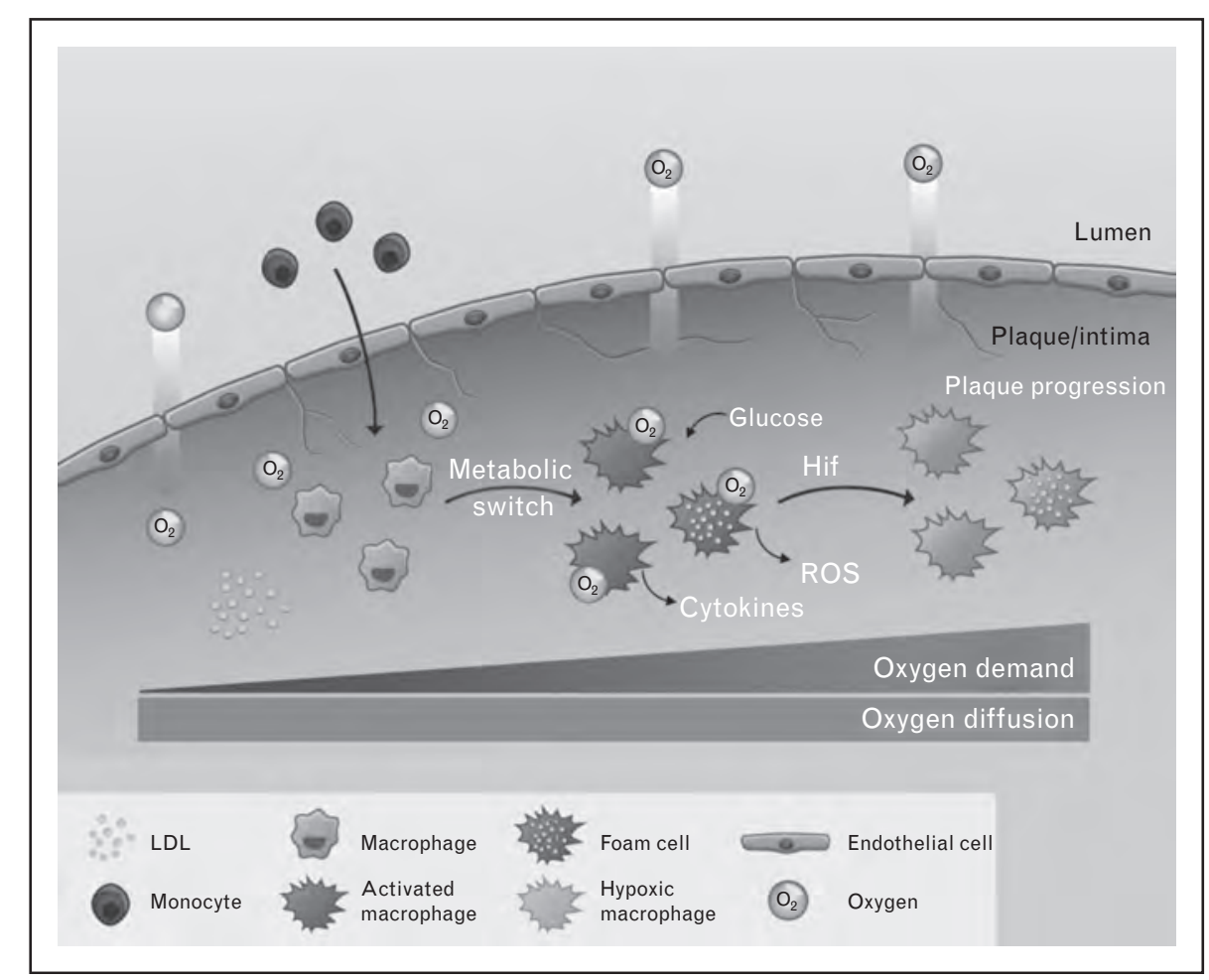

FIGURE 1. Suggested model of plaque oxygen availability and metabolic effects on macrophages. Upon entering the arterial wall, monocytes differentiate into macrophages, which in turn take up oxLDL and become activated. With increased inflammation, cytokine and ROS production, as well as glucose and ATP demand, macrophage oxygen consumption exceeds oxygen availability. Consequently, macrophages display signs of hypoxia, contributing to plaque progression, even though oxygen diffusion rates from the lumen into the plaque remain constant (credit to Volker Zerbe, www.volker-zerbe.de). ROS, reactive oxygen species. 
HYPOXIA ALTERS MACROPHAGE POLARIZATION AND INFLAMIMATION

As indicated, hypoxia can induce the glycolytic switch and M1 macrophages show increased glycolytic activity [64]. It has therefore been speculated that hypoxia can promote proinflammatory M1 macrophage differentiation, thereby aggravating atherogenesis. However, there is conflicting evidence for a hypoxia-mediated M1 macrophage phenotype switch. In vitro, macrophages display M1 polarization upon hypoxia [81"] and Hif- $1 \alpha$ knockout macrophages present a M2 tumor-associated macrophage (TAM) marker profile [82]. However, in vivo, M2 TAMs accumulate in hypoxic tumor regions and both M1 and M2 adipose tissue macrophages (ATMs) amass in distinct hypoxic adipose tissue $\left[81^{\prime}, 82\right]$. These data suggest the presence of an additional M2 macrophage trigger overriding hypoxia in inflammatory tissue in vivo. In this respect, lactate and $\mathrm{pH}$, as well as growth factors and necrotic debris, have been described for the tumor environment [83], suggesting a secondary effect of the Warburg effect and lactate production on M2 polarization.

In atherosclerotic lesions, both M1 and M2 macrophage populations increased during plaque progression towards unstable lesions in vivo, with M1 macrophages localizing in rupture-prone areas [84"]. Also, studies on tumor hypoxia and macrophage distribution show that mainly M2-like TAMs are localized in hypoxic regions [85], supporting the idea of an additional trigger towards M2-like macrophage marker expression overriding hypoxia. This is not surprising, as the plaque and tumor environment are very heterogeneous and contain various growth factors and inflammatory mediators. In this respect, we suggest that atherosclerotic plaque macrophages might resemble the tumor macrophages.

In conclusion, hypoxia seems to induce proinflammatory responses in macrophages. However, hypoxia is not sufficient in inducing macrophage phenotype switching in vivo, as it is balanced by yet unknown factors.

\section{HYPOXIA AS A NONINVASIVE IMAGING TOOL OF ATHEROSCLEROSIS}

Knowing the proatherosclerotic role of hypoxia, imaging of plaque hypoxia may become a relevant and desirable prognostic and diagnostic tool for atherosclerosis. Several imidazole analogs $\left[{ }^{18} \mathrm{~F}\right]$-EF5 [86], $\left[{ }^{18} \mathrm{~F}\right]-\mathrm{HX} 4$ (3-[ $\left[{ }^{18} \mathrm{~F}\right]$ fluoro-2-[4-(2-nitro-1Himida zol-1-yl)methyl)-1H-1,2,3,-triazol-1-yl]-propan-1-ol) [87] and 18F-fluoromisonidazole ([18 $\left.{ }^{8} \mathrm{~F}\right]$-MISO) [88"-] have been positively tested in imaging of hypoxia in tumors; however, they remain to be validated in atherosclerosis imaging. Recently, hypoxic atherosclerotic areas in $\mathrm{LDLR}^{-/-} \mathrm{ApoB}^{100 / 100}$ mice were successfully imaged ex vivo using $\left[{ }^{18} \mathrm{~F}\right]-\mathrm{EF} 5$ and PET scan. $\left[{ }^{18} \mathrm{~F}\right]$-EF5 signal on autoradiography was significantly higher in atherosclerotic plaques compared to the normal arterial vessel wall and uptake was independent of calcification and, surprisingly, inflammatory state of the plaque [11]. Recent studies and the above described metabolic shift in plaque macrophages suggest that the metabolic marker ${ }^{18}$ F-fluorodeoxyglucose $\left({ }^{18} \mathrm{~F}\right.$-FDG) can be used as an indirect marker of hypoxia in vivo. ${ }^{18} \mathrm{~F}-\mathrm{FDG}$ is a glucose analog PET tracer, which is taken up particularly by highly proliferative and glycolytically active cells and has hence also been linked with inflammation. In-vitro data show that glucose uptake in human macrophages is stimulated to a greater extent by hypoxic conditions as compared to inflammatory triggers [65], suggesting that ${ }^{18}$ F-FDG uptake can be used to visualize plaque hypoxia. In vivo, ${ }^{18} \mathrm{~F}-\mathrm{FDG}$ positivity has been linked with tumor inflammation and also atherosclerotic plaques could be detected in oncology patients [89-92]. However, there is conflicting evidence for the effectiveness of ${ }^{18} \mathrm{~F}$-FDG as a hypoxic marker. Whereas ${ }^{18}$ F-FDG did not correlate well with ${ }^{18}$ F-MISO in sarcomas [93], ${ }^{18}$ F-FDG PET signal positivity correlated with hypoxia-mediated gene expression in murine atherosclerosis, including genes like Hif- $1 \alpha$ and VEGF [94"]. Only a few human atherosclerosis imaging studies have been performed so far [95]. These correlate the ${ }^{18}$ F-FDG uptake to macrophage presence in the plaque, and symptomatic unstable plaques show greater ${ }^{18}$ F-FDG uptake compared to advanced plaques $\left[92,94^{*}, 96,97\right]$. Thus, ${ }^{18}$ F-FDG represents an indirect tool to measure hypoxia and inflammation in atherosclerotic plaques and was recently successfully used to monitor decreases in human plaque inflammation under atorvastatin, pioglitazone and the HDL-raising compound dalcetrapib [98]. A combination with imidazole-based hypoxia PET scan markers and 18F-FDG may prove useful in diagnosis of plaque phenotypes and plaque progression.

\section{CONCLUSION}

Recent studies have confirmed the presence of hypoxia in atherosclerotic plaques and its co-localization with macrophages. Systemic hypoxia sleep apnea models and clinical studies reveal the proatherosclerotic role of hypoxia and mechanistically link hypoxia with impaired macrophage function. Intracellular lipid accumulation and LDL oxidation and macrophage glucose metabolism are induced, 
resulting in ROS signaling, lactate production and acceleration of disease.

From this evidence, we conclude that hypoxia may well represent one of the main drivers of atherosclerosis by interfering with macrophage function. Additionally, recent evidence interlinks plaque hypoxia with macrophage metabolic changes; however, a causal relationship remains to be established.

\section{Acknowledgements}

Research was supported by a VENI fellowship of the Netherlands Organization of Scientific research (to J.C.S. 016.116.017).

\section{Conflicts of interest}

None declared.

\section{REFERENCES AND RECOMMENDED}

\section{READING}

Papers of particular interest, published within the annual period of review, have been highlighted as:

- of special interest

-1. of outstanding interest

Additional references related to this topic can also be found in the Current

World Literature section in this issue (p. 445).

1. Crawford DW, Kramsch DM. The oxygen environment of the arterial media in early rabbit hypertension. Exp Molec Pathol 1988; 49:215-233.

2. Martin JF, Booth RF, Moncada S. Arterial wall hypoxia following hyperfusion through the vasa vasorum is an initial lesion in atherosclerosis. Eur J Clin Investig 1990; 20:588-592.

3. Heughan C, Niinikoski J, Hunt TK. Oxygen tensions in lesions of experimental atherosclerosis of rabbits. Atherosclerosis 1973; 17:361-367.

4. Jurrus ER, Weiss HS. In vitro tissue oxygen tensions in the rabbit aortic arch. Atherosclerosis 1977; 28:223-232.

5. Niinikoski J, Heughan $\mathrm{C}$, Hunt TK. Oxygen tensions in the aortic wall of normal rabbits. Atherosclerosis 1973; 17:353-359.

6. Björnheden T, Evaldsson M, Wiklund O. A method for the assessment of hypoxia in the arterial wall, with potential application in vivo. Arterioscler Thromb Vasc Biol 1996; 16:178-185.

7. Björnheden $T$, Levin $M$, Evaldsson $M$, et al. Evidence of hypoxic areas within the arterial wall in vivo. Arterioscler Thromb Vasc Biol 1999; 19:870-876.

8. Joseph P, Jaiswal AK, Stobbe CC, et al. The role of specific reductases in the intracellular activation and binding of 2-nitroimidazoles. Int J Radiat Oncol Biol Phys $1994 ; 29: 351-355$.

9. NPI Inc. Hypoxyprobe 2013.

10. Sluimer JC, Gasc J-M, Van Wanroij JL, et al. Hypoxia, hypoxia-inducible transcription factor, and macrophages in human atherosclerotic plaques are correlated with intraplaque angiogenesis. J Am Coll Cardiol 2008; 51:1258-1265.

11. Silvola JMU, Saraste A, Forsback $S$, et al. Detection of hypoxia by [18F]EF5 in atherosclerotic plaques in mice. Arterioscler Thromb Vasc Biol 2011; 31:1011-1015.

12. Ramkhelawon $B$, Yang $Y$, Van Gils JM, et al. Hypoxia induces netrin-1 and

- Unc5b in atherosclerotic plaques: mechanism for macrophage retention and survival. Arterioscler Thromb Vasc Biol 2013; 33:1180-1188.

This study demonstrates plaque hypoxia in LDLr-I- plaque macrophages and colocalizes hypoxia with Hif- $1 \alpha$ - induced netrin-1 and unc5b expression

13. Rey S, Semenza GL. Hypoxia-inducible factor-1-dependent mechanisms of vascularization and vascular remodelling. Cardiovasc Res 2010; 86:236242.

14. Gao L, Chen $\mathrm{Q}$, Zhou $X$, et al. The role of hypoxia-inducible factor 1 in

- atherosclerosis. J Clin Pathol 2012; 65:872-876.

This recent review summarizes the pathological role of Hif- 1 alpha in atherosclero-

tic plaque progression.

15. Semenza GL. Hypoxia-inducible factor 1: regulator of mitochondrial metabolism and mediator of ischemic preconditioning. Biochim Biophys Acta 2011; 1813:1263-1268.

16. Semenza GL. Hypoxia-inducible factors in physiology and medicine. Cell 2012; 148:399-408.
17. Wang GL, Jiang $B H$, Rue EA, et al. Hypoxia-inducible factor 1 is a basic-helixloop-helix-PAS heterodimer regulated by cellular O2 tension. Proc Natl Acad Sci U S A 1995; 92:5510-5514.

18. Richard DE, Berra E, Pouyssegur J. Nonhypoxic pathway mediates the induction of hypoxia-inducible factor 1 alpha in vascular smooth muscle cells. J Biol Chem 2000; 275:26765-26771.

19. Görlach A, Diebold I, Schini-Kerth VB, et al. Thrombin activates the hypoxiainducible factor-1 signaling pathway in vascular smooth muscle cells: role of the p22(phox)-containing NADPH oxidase. Circ Res 2001; 89:47-54.

20. Nishi $K$, Oda T, Takabuchi $S$, et al. LPS induces hypoxia-inducible factor 1 activation in macrophage-differentiated cells in a reactive oxygen speciesdependent manner. Antioxid Redox Signal 2008; 10:983-995.

21. Shatrov VA, Sumbayev VV, Zhou J, et al. Oxidized low-density lipoprotein (oxLDL) triggers hypoxia-inducible factor-1alpha (HIF-1alpha) accumulation via redox-dependent mechanisms. Blood 2003; 101:4847-4849.

22. De Ponti $\mathrm{C}$, Carini $\mathrm{R}$, Alchera $\mathrm{E}$, et al. Adenosine A2a receptor-mediated, normoxic induction of HIF-1 through PKC and PI-3K-dependent pathways in macrophages. J Leukoc Biol 2007; 82:392-402.

23. The Lancet. The global burden of disease study 2010. Lancet 2012.

24. Baguet J-P, Barone-Rochette G, Tamisier R, et al. Mechanisms of cardiac dysfunction in obstructive sleep apnea. Nat Rev Cardiol 2012; 9:679-688.

25. Mooe $T$, Franklin KA, Holmström $\mathrm{K}$, et al. Sleep-disordered breathing and coronary artery disease: long-term prognosis. Am J Respirat Crit Care Med 2001; 164:1910-1913

26. Drager LF, Polotsky VY, Lorenzi-Filho G. Obstructive sleep apnea: an emerging risk factor for atherosclerosis. Chest 2011; 140:534-542.

27. Bradley TD, Floras JS. Obstructive sleep apnoea and its cardiovascular consequences. Lancet 2009; 373:82-93.

28. Mokhlesi B, Gozal D. Update in sleep medicine 2009. Am J Respirat Crit Care Med 2010; 181:545-549.

29. Lévy P, Pépin JL, Arnaud C. Obstructive sleep apnea and atherosclerosis. Prog Cardiovasc Dis 2009; 51:400-410.

30. Yaggi HK, Concato J, Kernan WN, et al. Obstructive sleep apnea as a risk factor for stroke and death. N Engl J Med 2005; 353:2034-2041.

31. Fletcher EC. Invited review: physiological consequences of intermittent hypoxia: systemic blood pressure. J Appl Physiol 2001; 90:1600-1605; Bethesda, Maryland, 2005

32. Yamauchi $\mathrm{M}$, Kimura $\mathrm{H}$. Oxidative stress in obstructive sleep apnea: putative pathways to the cardiovascular complications. Antioxid Redox Signal 2008; 10:755-768.

33. Jun J, Reinke C, Bedja D, et al. Effect of intermittent hypoxia on atherosclerosis in apolipoprotein E-deficient mice. Atherosclerosis 2010; 209:381-386.

34. Savransky V, Nanayakkara A, Li J, et al. Chronic intermittent hypoxia induces atherosclerosis. Am J Respirat Crit Care Med 2007; 175:1290-1297.

35. Nakano $\mathrm{D}$, Hayashi $\mathrm{T}$, Tazawa $\mathrm{N}$, et al. Chronic hypoxia accelerates the progression of atherosclerosis in apolipoprotein E-knockout mice. Hypertens Res 2005; 28:837-845

36. Fang $G$, Song $D, Y e X$, et al. Chronic intermittent hypoxia exposure induces atherosclerosis in ApoE knockout mice: role of NF-кB p50. Am J Pathol 2012; 181:1530-1539.

37. Büchner NJ, QuackI, Woznowski M, et al. Microvascular endothelial dysfunction in obstructive sleep apnea is caused by oxidative stress and improved by continuous positive airway pressure therapy. Respiration $2011 ; 82: 409-417$.

38. Drager LF, Bortolotto LA, Figueiredo AC, et al. Effects of continuous positive airway pressure on early signs of atherosclerosis in obstructive sleep apnea. Am J Respirat Crit Care Med 2007; 176:706-712.

39. Kudchodkar BJ, Wilson J, Lacko A, et al. Hyperbaric oxygen reduces the progression and accelerates the regression of atherosclerosis in rabbits. Arterioscler Thromb Vasc Biol 2000; 20:1637-1643.

40. Kudchodkar BJ, Pierce A, Dory L. Chronic hyperbaric oxygen treatment elicits an antioxidant response and attenuates atherosclerosis in apoE knockout mice. Atherosclerosis $2007 ; 193: 28-35$.

41. Kudchodkar B, Jones $H$, Simecka J, et al. Hyperbaric oxygen treatment attenuates the pro-inflammatory and immune responses in apolipoprotein $\mathrm{E}$ knockout mice. Clin Immunol (Orlando, Florida) 2008; 128:435-441.

42. Karadurmus $N$, Sahin $M$, Tasci $C$. Potential benefits of hyperbaric oxygen therapy on atherosclerosis and glycaemic control in patients with diabetic foot. Endokrynologia Polska 2010; 61:275-279.

43. Chen S-Y, Huang E, Wang V. Improvement of clinical outcome and cerebral perfusion in a patient of atherosclerotic cerebral infarction after repetitive hyperbaric oxygen treatment: a case report and literature review. Undersea Hyperbaric Med 2011; 38:375-379.

44. Unfirer S, Kibel A, Drenjancevic-Peric I. The effect of hyperbaric oxygen therapy on blood vessel function in diabetes mellitus. Med Hypotheses 2008; 71:776-780.

45. Lokmic Z, Musyoka J, Hewitson TD, et al. Hypoxia and hypoxia signaling in - tissue repair and fibrosis. Int Rev Cell Molec Biol 2012; 296:139-185.

This review integrates hypoxia-mediated inflammatory signaling with tissue repair signaling, fibrosis and sclerosis.

46. Li L, Liu B, Håversen L, et al. The importance of GLUT3 for de novo - lipogenesis in hypoxia-induced lipid loading of human macrophages. PloS One 2012; $7: \mathrm{e} 42360$.

These authors establish a novel link between increased glucose uptake via GLUT3 and increased triglyceride synthesis from glucose in hypoxic plaque macrophages. 
47. Na TY, Lee HJ, Oh HJ, et al. Positive cross-talk between hypoxia inducible factor- $1 \alpha$ and liver $\mathrm{X}$ receptor $\alpha$ induces formation of triglyceride-loaded foam cells. Arterioscler Thromb Vasc Biol 2011; 31:2949-2956.

48. Asplund A, Fridén V, Stillemark-Billton $P$, et al. Macrophages exposed to hypoxia secrete proteoglycans for which LDL has higher affinity. Atherosclerosis 2011; 215:77-81.

49. Parathath $S$, Yang $Y$, Mick $S$, et al. Hypoxia in murine atherosclerotic plaques

- and its adverse effects on macrophages. Trends Cardiovasc Med 2013; 23:80-84.

A timely review of hypoxia and hypoxia-inducible factor-mediated effects on lipid metabolism in macrophages.

50. Jiang G, Li T, Qiu Y, et al. RNA interference for HIF-1alpha inhibits foam cells formation in vitro. Eur J Pharmacol 2007; 562:183-190.

51. Parathath S, Mick SL, Feig JE, et al. Hypoxia is present in murine atherosclerotic plaques and has multiple adverse effects on macrophage lipid metabolism. Circ Res 2011; 109:1141-1152.

52. Song D, Fang G, Mao SZ, et al. Chronic intermittent hypoxia induces

- atherosclerosis by NF-кB-dependent mechanisms. Biochim Biophys Acta 2012; 1822:1650-1659.

This study shows the link between hypoxia and inflammatory signaling and how hypoxia can induce NF-кB-mediated atherogenesis.

53. Kanters E, Gijbels MJJ, Van der Made I, et al. Hematopoietic NF-kappaB1 deficiency results in small atherosclerotic lesions with an inflammatory phenotype. Blood 2004; 103:934-940.

54. Drager LF, Yao Q, Hernandez KL, et al. Chronic intermittent hypoxia induces

- atherosclerosis via activation of adipose angiopoietin-like 4. Am J Respirat Crit Care Med 2013.

In this study, the authors describe a novel mechanism of hypoxia-mediated dyslipidemia and atherosclerosis involving activation of adipose angiopoietinlike 4.

55. Li RC, Haribabu B, Mathis SP, et al. Leukotriene B4 receptor-1 mediates intermittent hypoxia-induced atherogenesis. Am J Respirat Crit Care Med $2011 ; 184: 124-131$.

56. Wang $B$, Yan B, Song $D$, et al. Chronic intermittent hypoxia down-regulates

- endothelial nitric oxide synthase expression by an NF- $\mathrm{kB}$-dependent mechanism. Sleep Med 2013; 14:165-171.

These investigators establish a link between hypoxia-mediated increased inflammation and endothelial dysfunction seen in OSA patients.

57. Johnson AR, Freemerman AJ, Abel E, et al. Glucose metabolism is linked to

- the inflammatory status of macrophages. BMC Proc 2012; 6:62.

By inhibiting glucose metabolism, these authors demonstrate the link between high glucose metabolism and pro-inflammatory status of macrophages.

58. Fang $\mathrm{H}-\mathrm{Y}$, Hughes $\mathrm{R}$, Murdoch $\mathrm{C}$, et al. Hypoxia-inducible factors 1 and 2 are important transcriptional effectors in primary macrophages experiencing hypoxia. Blood 2009; 114:844-859.

59. Oda T, Hirota K, Nishi K, et al. Activation of hypoxia-inducible factor 1 during macrophage differentiation. Am J Physiol Cell Physiol 2006; 291:C104C113.

60. Warburg O, Wind F, Negelein E. The metabolism of tumors in the body. J Gen Physiol 1927; 8:519-530.

61. Vander Heiden MG, Cantley LC, Thompson CB. Understanding the Warburg effect: the metabolic requirements of cell proliferation. Science (New York, NY) 2009; 324:1029-1033.

62. Wang $R$, Dillon $C P$, Shi $L Z$, et al. The transcription factor Myc controls metabolic reprogramming upon T lymphocyte activation. Immunity 2011; 35:871-882.

63. Murdoch $C$, Muthana $M$, Lewis $C E$. Hypoxia regulates macrophage functions in inflammation. J Immunol 2005; 175:6257-6263. (Baltimore, Maryland: 1950).

64. Kawaguchi T, Veech RL, Uyeda K. Regulation of energy metabolism in macrophages during hypoxia. Roles of fructose 2,6-bisphosphate and ribose 1,5-bisphosphate. J Biol Chem 2001; 276:28554-28561.

65. Folco EJ, Sheikine Y, Rocha VZ, et al. Hypoxia but not inflammation augments glucose uptake in human macrophages: implications for imaging atherosclerosis with 18 fluorine-labeled 2-deoxy-D-glucose positron emission tomography. J Am Coll Cardiol 2011; 58:603-614.

66. O'Neill LAJ, Hardie DG. Metabolism of inflammation limited by AMPK and pseudo-starvation. Nature 2013; 493:346-355.

An excellent review discussing the connection between metabolic changes and inflammatory signaling.

67. Leppänen $\mathrm{O}$, Björnheden $\mathrm{T}$, Evaldsson $\mathrm{M}$, et al. ATP depletion in macrophages in the core of advanced rabbit atherosclerotic plaques in vivo. Atherosclerosis 2006; 188:323-330.

68. Shantha GPS, Wasserman B, Astor BC, et al. Association of blood lactate with carotid atherosclerosis: The Atherosclerosis Risk in Communities (ARIC) Carotid MRI Study. Atherosclerosis 2013; 228:249-255.

69. Ö̈rni K, Kovanen PT. Enhanced extracellular lipid accumulation in acidic environments. Curr Opin Lipidol 2006; 17:534-540.

70. Khazaei M, Nematbakhsh M. Effect of experimentally induced metabolic acidosis on aortic endothelial permeability and serum nitric oxide concentration in normal and high-cholesterol fed rabbits. Arch Med Sci 2012; 8:719723.
71. Murphy MP. How mitochondria produce reactive oxygen species. Biochem J 2009; 417:1-13.

72. Violi $\mathrm{F}$, Basili $\mathrm{S}$, Nigro $\mathrm{C}$, et al. Role of NADPH oxidase in atherosclerosis. Future Cardiol 2009; 5:83-92.

73. Vogiatzi G, Tousoulis D, Stefanadis $C$. The role of oxidative stress in atherosclerosis. Hellenic J Cardiol 2009; 50:402-409.

74. Klimova T, Chandel NS. Mitochondrial complex III regulates hypoxic activation of HIF. Cell Death Differ 2008; 15:660-666.

75. Tavakoli $\mathrm{S}$, Asmis R. Reactive oxygen species and thiol redox signaling in the

- macrophage biology of atherosclerosis. Antioxid Redox Signal 2012; 17: $1785-1795$.

An up-to-date review on ROS signaling in atherosclerotic macrophages and how

ROS contribute to pathogenesis.

76. Schaefer CA, Kuhlmann CRW, Weiterer S, et al. Statins inhibit hypoxiainduced endothelial proliferation by preventing calcium-induced ROS formation. Atherosclerosis 2006; 185:290-296.

77. Christou K, Kostikas K, Pastaka C, et al. Nasal continuous positive airway pressure treatment reduces systemic oxidative stress in patients with severe obstructive sleep apnea syndrome. Sleep Med 2009; 10:87-94.

78. Del Ben M, Fabiani M, Loffredo $L$, et al. Oxidative stress mediated arterial

- dysfunction in patients with obstructive sleep apnoea and the effect of continuous positive airway pressure treatment. BMC Pulmonary Med $2012 ; 12: 36$.

This study shows that OSA patients present with elevated oxidative stress levels and arterial dysfunction, which can be partially reversed by continuous positive airway pressure treatment.

79. Schulz R, Mahmoudi S, Hattar K, et al. Enhanced release of superoxide from polymorphonuclear neutrophils in obstructive sleep apnea. Impact of continuous positive airway pressure therapy. Am J Respirat Crit Care Med 2000; $162: 566-570$

80. Lavie L. Oxidative stress inflammation and endothelial dysfunction in obstructive sleep apnea. Front Biosci (Elite Edition) 2012; 4:1391-1403.

This recent review summarizes the evidence for a pro-atherosclerotic role of oxidative stress and endothelial dysfunction in obstructive sleep apnea patients and models.

81. Fujisaka S, Usui I, Ikutani M, et al. Adipose tissue hypoxia induces inflamma-

- tory M1 polarity of macrophages in an HIF- $1 \alpha$-dependent and HIF- $1 \alpha$-independent manner in obese mice. Diabetologia 2013; 56:1403-1412.

This study nicely shows how hypoxia can induce pro-inflammatory M1 polarity in a tissue-specific manner in vitro.

82. Werno $\mathrm{C}$, Menrad $\mathrm{H}$, Weigert $\mathrm{A}$, et al. Knockout of HIF-1 $\alpha$ in tumor-associated macrophages enhances M2 polarization and attenuates their pro-angiogenic responses. Carcinogenesis 2010; 31:1863-1872.

83. Lewis C, Murdoch C. Macrophage responses to hypoxia: implications for tumor progression and anticancer therapies. Am J Pathol 2005; 167:627635.

84. Stöger JL, Gijbels MJJ, Van der Velden S, et al. Distribution of macrophage

- polarization markers in human atherosclerosis. Atherosclerosis 2012; 225:461-468

The authors link the presence of M1 and M2 macrophage populations to different areas within the plaque, while no clear association of specific populations with plaque types is found.

85. Laoui D, Van Overmeire E, Movahedi K, et al. Mononuclear phagocyte heterogeneity in cancer: different subsets and activation states reaching out at the tumor site. Immunobiology 2011; 216:1192-1202.

86. Abramson Cancer Center of the University of Pennsylvania. Fluorine F18-EF5 and fludeoxyglucose $F 18$ positron emission tomography in assessing hypoxia and glycolysis in patients with stage I, stage II, or stage III non-small cell lung cancer (Full Text View - ClinicalTrials.gov. Clinicaltrials.gov) 2012.

87. Van Loon J, Janssen MHM, Ollers $M$, et al. PET imaging of hypoxia using [18F]HX4: a phase I trial. Eur J Nuclear Med Molec Imag 2010; 37:16631668.

88. Tachibana I, Nishimura $Y$, Shibata $T$, et al. A prospective clinical trial of tumor

nypoxia imaging with 18F-fluoromisonidazole positron emission tomography and computed tomography (F-MISO PET/CT) before and during radiation therapy. J Radiat Res 2013.

In this study, tumor hypoxia is successfully visualized with the hypoxic tracer 18F-MISO. Hypoxic tumor areas were found in all patients and could be reversed after two weeks of fractionated radiation therapy.

89. Dunphy MPS, Freiman A, Larson SM, et al. Association of vascular 18F-FDG uptake with vascular calcification. J Nuclear Med 2005; 46: 1278-1284.

90. Tatsumi M, Cohade C, Nakamoto $\mathrm{Y}$, et al. Fluorodeoxyglucose uptake in the aortic wall at PET/CT: possible finding for active atherosclerosis. Radiology 2003; 229:831-837.

91. Yun $\mathrm{M}$, Yeh D, Araujo LI, et al. F-18 FDG uptake in the large arteries: a new observation. Clin Nuclear Med 2001; 26:314-319.

92. Bural GG, Torigian DA, Chamroonrat $W$, et al. FDG-PET is an effective imaging modality to detect and quantify age-related atherosclerosis in large arteries. Eur J Nuclear Med Molec Imag 2008; 35:562-569.

93. Rajendran JG, Wilson DC, Conrad EU, et al. [(18)F]FMISO and [(18)F]FDG PET imaging in soft tissue sarcomas: correlation of hypoxia, metabolism and VEGF expression. Eur J Nuclear Med Molec Imag 2003; 30:695-704. 
94. Hag AMF, Pedersen SF, Christoffersen C, et al. (18)F-FDG PET imaging of

- murine atherosclerosis: association with gene expression of key molecular markers. PloS One 2012; 7:e50908.

This study associates the uptake of the metabolic marker 18F-FDG with expression of key atherosclerosis markers, in particular VCAM, tissue factor (TF) and CD68.

95. Fayad ZA, Mani V, Woodward M, et al. Safety and efficacy of dalcetrapib on atherosclerotic disease using novel noninvasive multimodality imaging (dalPLAQUE): a randomised clinical trial. Lancet 2011; 378:1547-1559.
96. Tawakol A, Migrino RQ, Bashian GG, et al. In vivo 18F-fluorodeoxyglucose positron emission tomography imaging provides a noninvasive measure of carotid plaque inflammation in patients. J Am Coll Cardiol 2006; 48:18181824.

97. Kwee RM, Truijman MTB, Mess $\mathrm{WH}$, et al. Potential of integrated [18F] fluorodeoxyglucose positron-emission tomography/CT in identifying vulnerable carotid plaques. Am J Neuroradiol 2011; 32:950-954.

98. Rosenbaum D, Millon A, Fayad ZA. Molecular imaging in atherosclerosis: FDG PET. Current Atherosclerosis Reports 2012; 14:429-437. 